\title{
Review Article \\ Recognition of Dual or Multiple Pathology in Skin Biopsies from Patients with HIV/AIDS
}

\author{
Wayne Grayson ${ }^{1,2}$ \\ ${ }^{1}$ Drs Du Buisson, Kramer, Swart, Bouwer Inc., (AMPATH National Laboratories), Johannesburg 2092, South Africa \\ ${ }^{2}$ Division of Anatomical Pathology, School of Pathology, Faculty of Health Sciences, University of the Witwatersrand, \\ Johannesburg 2193, South Africa
}

Correspondence should be addressed to Wayne Grayson, wayne.grayson@live.com

Received 8 December 2010; Accepted 19 February 2011

Academic Editor: Liron Pantanowitz

Copyright (C) 2011 Wayne Grayson. This is an open access article distributed under the Creative Commons Attribution License, which permits unrestricted use, distribution, and reproduction in any medium, provided the original work is properly cited.

\begin{abstract}
A large percentage of patients with HIV/AIDS will develop dermatological complications. Consequently, all practising clinicians and pathologists in regions with a high prevalence of HIV/AIDS must be familiar with the diverse cutaneous manifestations of the disease. This paper highlights the fact that biopsy material in this clinical context may occasionally reveal more than one pathological process. The potential spectrum includes two or more infections in a single skin biopsy (e.g., herpes simplex and cytomegalovirus infection), neoplastic lesions containing infective organisms (Kaposi sarcoma (KS) and cryptococcosis), dermatoses in association with neoplastic lesions (e.g., KS and interface dermatitis), or more than one dermatosis in a given specimen (e.g., papulopruritic eruption and nodular prurigo). Rare biopsies may even demonstrate triple pathology. The importance of careful examination of skin biopsies in this clinical context is emphasised. Failure to recognise an undiagnosed concomitant opportunistic infective pathogen could have potentially disastrous consequences for the patient.
\end{abstract}

\section{Introduction}

Dermatological disorders are common in patients with human immunodeficiency virus (HIV) infection and the acquired immunodeficiency syndrome (AIDS). It is said that more than $90 \%$ of HIV+ patients will develop cutaneous complications during the course of their illness, and in a significant proportion of these individuals, skin lesions may be a presenting symptom or sign of previously undiagnosed HIV infection $[1,2]$. The spectrum of HIV-related skin disease includes a wide range of noninfective dermatoses, infective conditions, adverse drug reactions, and neoplastic proliferations [1]. It is not uncommon for this group of patients to manifest with more than one concurrent integumentary condition. Consequently, any given skin biopsy from an individual with cutaneous lesions in the presence of underlying HIV/AIDS could potentially reveal more than one pathological process. In severely immunosuppressed patients who have not received highly active antiretroviral therapy (HAART), subtle features of a coincidental potentially lethal opportunistic pathogen (e.g., cryptococcosis) can easily be overlooked in a specimen predominated by the primary pathological lesion (e.g., Kaposi sarcoma (KS)) [1, 3, 4]. Although dual or multiple pathological processes are seldom encountered in single skin biopsies in everyday practise, it is always wise to maintain a high index of suspicion when examining specimens from HIV/AIDS patients.

The main objective of this paper is to draw the surgical pathologist's attention to the potential spectrum of dual or multiple pathology, using personally encountered case examples to illustrate this uncommon phenomenon.

\section{Clinicopathological Spectrum}

2.1. Overview. Surprisingly little has been written on the subject, with single case reports comprising most of the rare examples cited in the literature. Consequently, it is difficult to ascertain what proportion of skin biopsies from patients with HIV/AIDS might harbour dual or multiple pathological lesions. Based on the author's experience, it would seem that a combination of lesions is probably encountered in less than $2 \%$ of cutaneous histological samples obtained from this group of patients. In a vast majority of documented cases, the detection of combined pathology has been a 


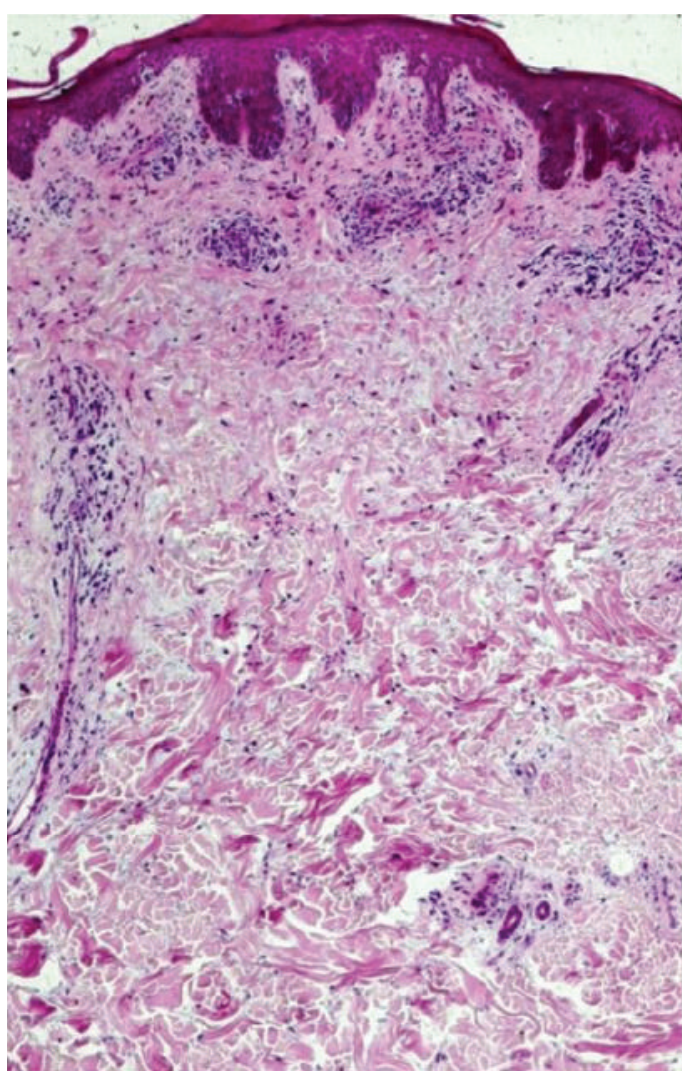

(a)

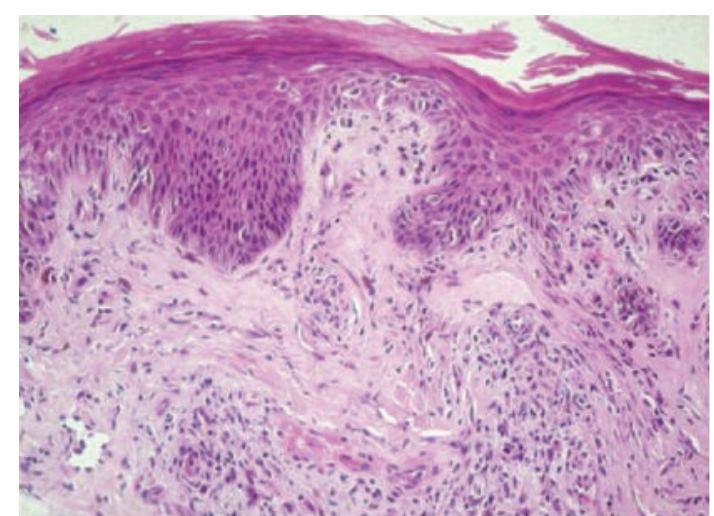

(b)

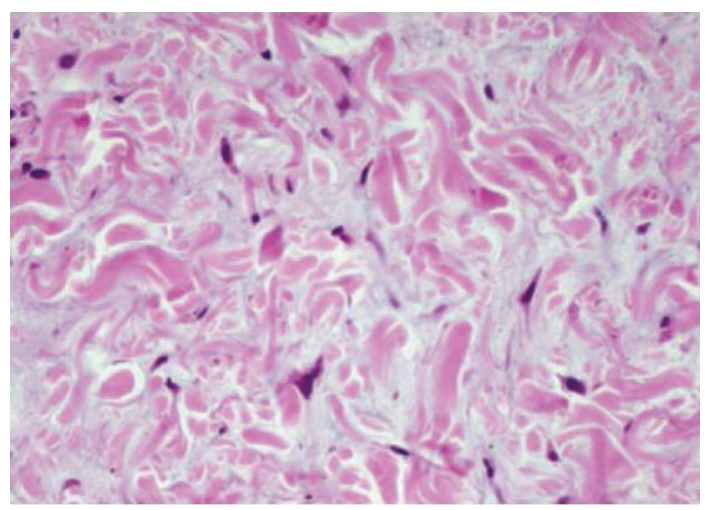

(c)

Figure 1: Papular mucinosis of HIV/AIDS. A mild superficial dermal mononuclear inflammatory infiltrate is associated with subacute eczematous changes in the overlying epidermis ( $\mathrm{a}, \mathrm{b})$, while the deeper dermis shows separation of collagen bundles by interstitial mucin (c).

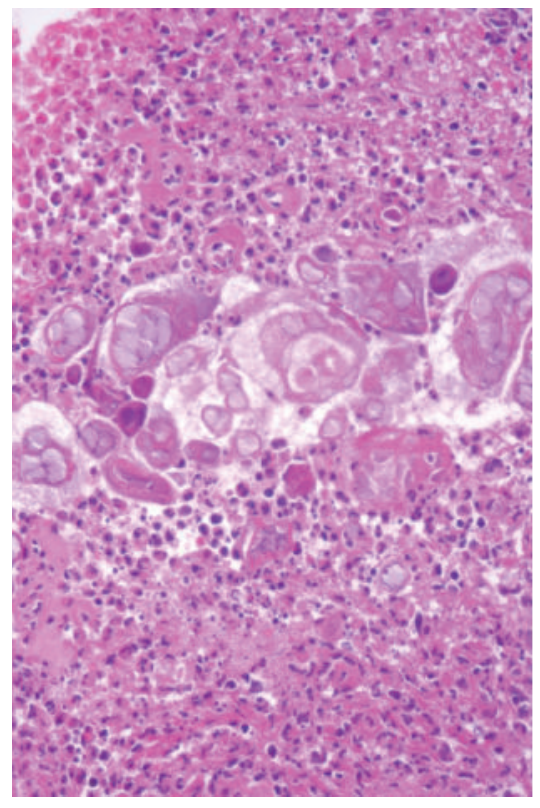

(a)

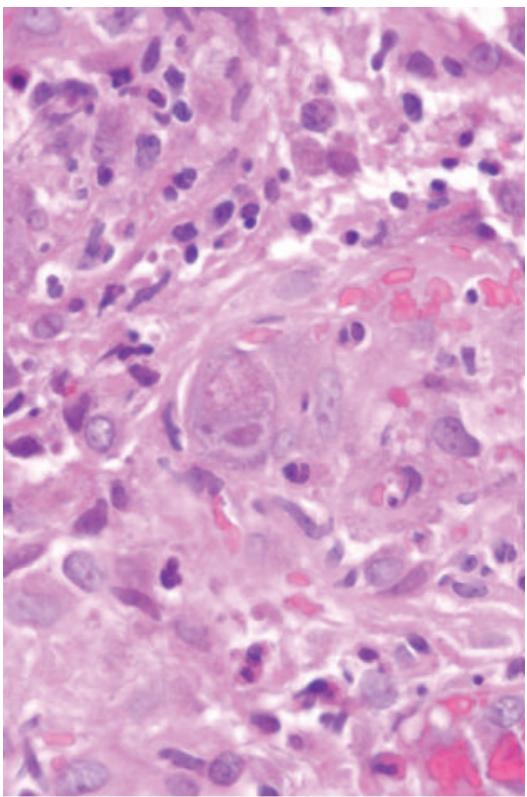

(b)

FIGURE 2: Biopsy of a vulval ulcer in a female patient with AIDS. (a) The ulcerated surface epithelium harbours many intranuclear herpes simplex virus inclusions. (b) Concomitant cytomegalovirus infection of an endothelial cell in the inflamed underlying dermis. 


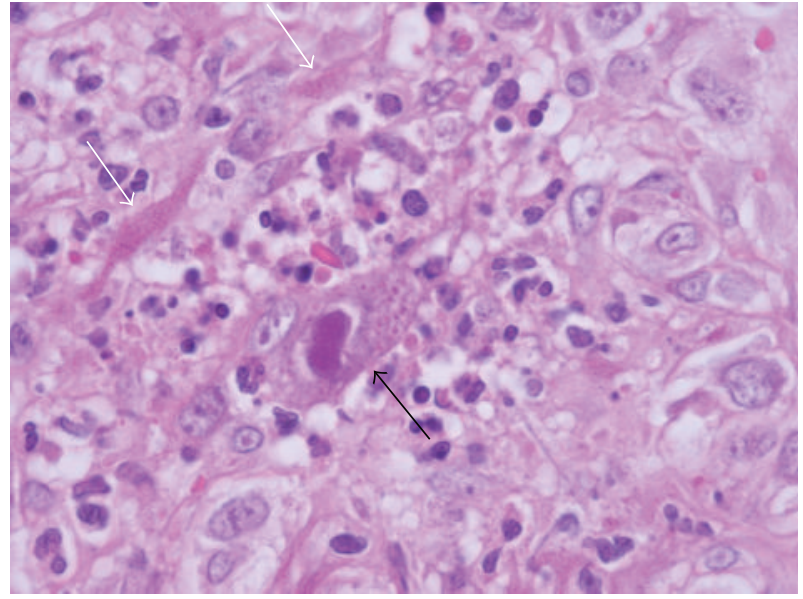

FIGURE 3: Bacillary angiomatosis with incidental cytomegalovirus (CMV) infection (black arrow). Granular colonies of extracellular Bartonella bacilli (white arrows) are present amid the background endothelial cell proliferation and infiltrate of polymorphonuclear leucocytes.

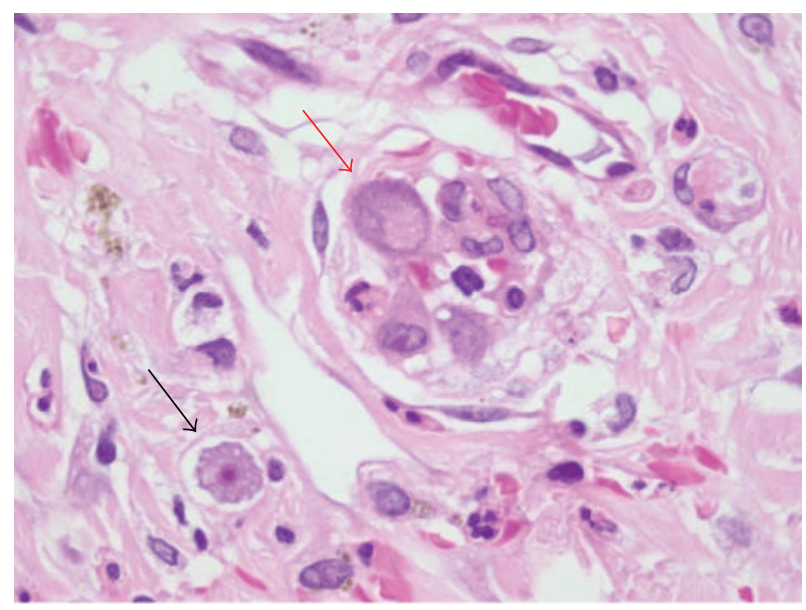

FIgure 4: Cutaneous Acanthamoeba infection (black arrow) with concomitant cytomegalovirus (CMV) infection (red arrow) in biopsy from a patient with advanced AIDS and widespread cutaneous ulceration.

reflection of marked underlying immunosuppression. Some more recently reported examples, however, have been a manifestation of the immune reconstitution inflammatory syndrome (IRIS) [3-5]. Although a detailed account of the cutaneous manifestations of IRIS is beyond the remit of this paper, many of the viral, fungal and bacterial infections alluded to below, and even neoplasms such as KS, may be a reflection of IRIS [3]. Satisfactory clinicopathological correlation is thus facilitated by knowledge of the patient's CD4 T-cell count and an indication of whether or not HAART has been implemented.

The wide spectrum of potential colesional skin biopsy pathology is outlined in Table 1. This spectrum encompasses dual noninfective dermatoses, dual or multiple infections,
TABLE 1: Overview of the potential spectrum of dual or multiple pathology in skin biopsies from patients with HIV/AIDS.

\begin{tabular}{|c|c|}
\hline Pathology & Reference(s) \\
\hline \multicolumn{2}{|l|}{ Dual noninfective dermatoses } \\
\hline PPE \& nodular prurigo & {$[1,6]$} \\
\hline $\begin{array}{l}\text { Papular mucinosis \& eczematous } \\
\text { dermatitis }\end{array}$ & {$[1,6-8]$} \\
\hline \multicolumn{2}{|l|}{ Dual infections } \\
\hline HSV \& CMV & {$[9-11]$} \\
\hline $\mathrm{BA} \& \mathrm{CMV}$ & {$[12]$} \\
\hline Mucormycosis \& CMV & {$[13]$} \\
\hline Acanthamoebiasis \& CMV & $\mathrm{U}$ \\
\hline $\begin{array}{l}\text { Pneumocystosis \& S. aureus } \\
\text { (botryomycosis) }\end{array}$ & {$[18]$} \\
\hline Pneumocystosis \& cryptococcosis & {$[19]$} \\
\hline MAI \& BA & {$[5,20]$} \\
\hline \multicolumn{2}{|l|}{ Dual infective and noninfective dermatoses } \\
\hline Histoplasmosis \& erythema multiforme & $\mathrm{U}$ \\
\hline Folliculitis \& interface dermatitis & $\mathrm{U}$ \\
\hline \multicolumn{2}{|l|}{ Neoplasia in association with infection } \\
\hline KS \& cryptococcosis & {$[3,4,23-25]$} \\
\hline KS \& Histoplasma capsulatum infection & {$[28]$} \\
\hline KS \& Candida infection & {$[29]$} \\
\hline KS \& MAI infection & {$[33-35]$} \\
\hline $\mathrm{KS} \& \mathrm{~Tb}$ & {$[3,37]$} \\
\hline KS \& CMV & {$[3,38]$} \\
\hline KS \& molluscum contagiosum & {$[3,40]$} \\
\hline NHL \& MAI infection & [35] \\
\hline$\left(\mathrm{KS} \& \mathrm{BA}^{*}\right)$ & {$[30,32]$} \\
\hline
\end{tabular}

Neoplasia in association with noninfective dermatoses

KS \& incidental interface dermatitis

KS \& acquired ichthyosis

Dual neoplastic lesions

KS \& penile squamous cell carcinoma in situ

Multiple pathology

MAI infection, KS, \& cryptococcosis

$\mathrm{BA}, \mathrm{MAI}, \& \mathrm{CMV}$

$[47,48]$

MAI \& CMV \& Tb

S. aureus, CMV, \& Mycobacterium spp.

VZV infection, LCV, \& KS

PPE: pruritic papular eruption of HIV; HSV: herpes simplex virus; CMV: cytomegalovirus; BA: bacillary angiomatosis; U: hitherto unreported; MAI: Mycobacterium avium-intracellulare complex; S. aureus: Staphylococcus aureus; Tb: Mycobacterium tuberculosis; KS: Kaposi sarcoma; NHL: nonHodgkin lymphoma; VZV: varicella-zoster virus; LCV: leucocytoclastic vasculitis.

* Recorded concurrently in the same patient, but not in the same histological specimen. 


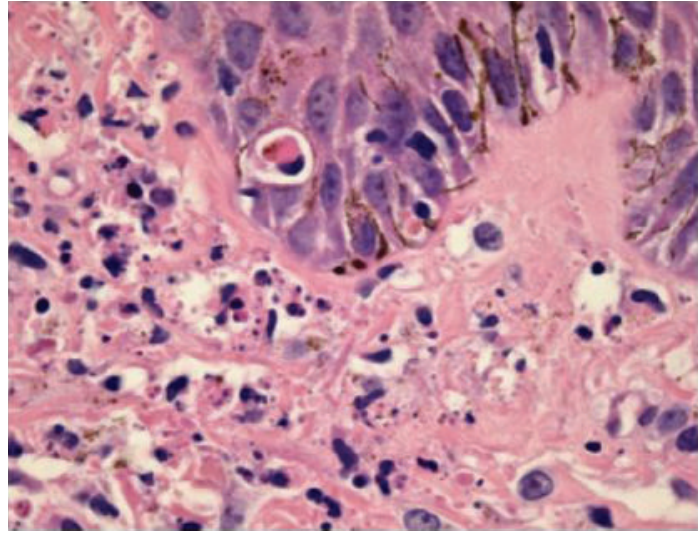

(a)

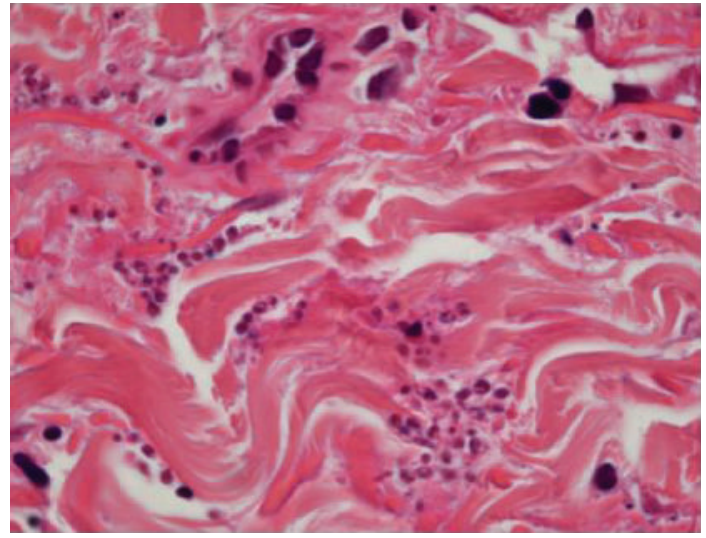

(b)

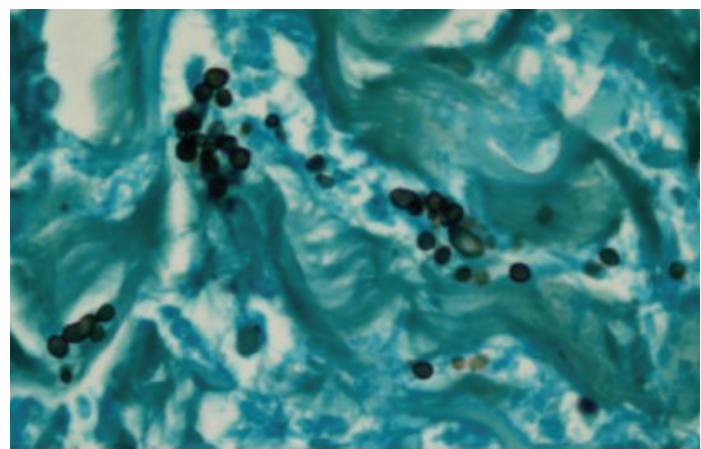

(c)

FIGURE 5: Skin biopsy from a patient with AIDS-associated histoplasmosis and concomitant erythema multiforme. A lichenoid reaction is visible in relation to the dermoepidermal interface (a), while the dermis contains conspicuous numbers of Histoplasma capsulatum yeasts (b), whose presence is highlighted with the aid of a Grocott stain (c).

neoplasia (KS) in association with infection, neoplasia (KS) with an associated dermatosis, mixed infective and inflammatory dermatoses, dual neoplastic conditions, and multiple pathologies. Although this latter group is uncommon, a high index of suspicion should always be maintained [1]. In most cases, the detection of more than one pathological lesion in a single biopsy is fortuitous and unexpected. On other occasions, however, a detailed history might reveal that the patient has clinical evidence of more than one type of skin lesion. Some dermatologists may therefore elect to intentionally sample overlapping lesions in a single biopsy [1].

2.2. Dual Noninfective Dermatoses. Since HIV/AIDS may be associated with a diverse array of noninfective dermatological disorders, and patients may often have more than one skin disease at presentation, it is somewhat surprising that skin biopsy specimens seldom reveal dual pathology of a noninfective nature. Two conditions, however, are known to sometimes demonstrate dual pathology. The first of these is pruritic papular eruption of HIV (papulopruritic eruption), where the longstanding pruritis and excoriation may be complicated by superimposed changes of nodular prurigo [6]. The second condition is papular mucinosis of HIV/AIDS, where intradermal mucin deposition is accompanied by concomitant epidermal changes of an eczematous dermatitis, as illustrated in Figure 1 [6-8].

2.3. Dual Infections. The increased susceptibility to infection by a wide range of opportunistic pathogens is a hallmark of HIV/AIDS. It is, therefore, essential that histological specimens in this clinical context are always examined carefully to ensure that a second (or perhaps even a third) infective organism is not overlooked [1]. The most frequently encountered copathogen is cytomegalovirus (CMV). CMV is often identified in the dermis in biopsies obtained from genital or perineal ulcers caused by herpes simplex virus (Figure 2), and associated vasculitis is not uncommon [1,9-11].

CMV infection has also been documented in association with bacillary angiomatosis (BA) (Figure 3) and mucormycosis $[12,13]$. The author has also encountered a case of widespread cutaneous ulceration due to vasculitis in the presence of acanthamoebiasis and concomitant CMV infection (Figure 4). Although skin lesions due to infection with Acanthamoeba spp. may occur in patients with AIDS, to date there have been no additional examples with CMV coinfection recorded in the literature [14-17]. 


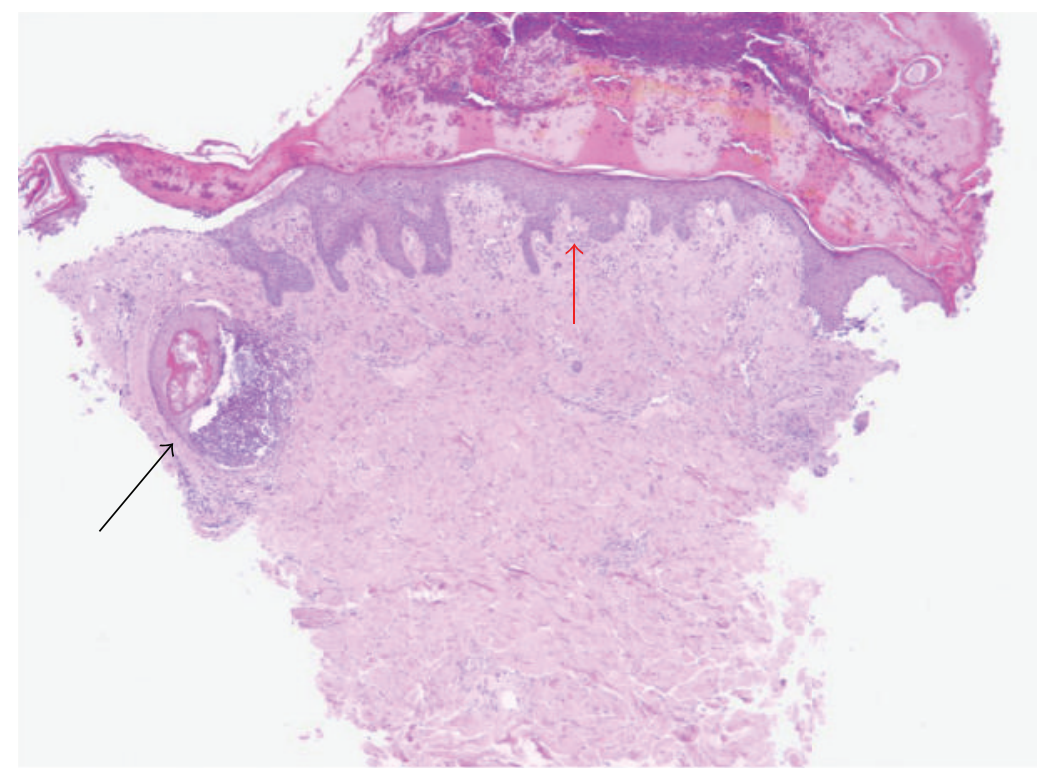

(a)

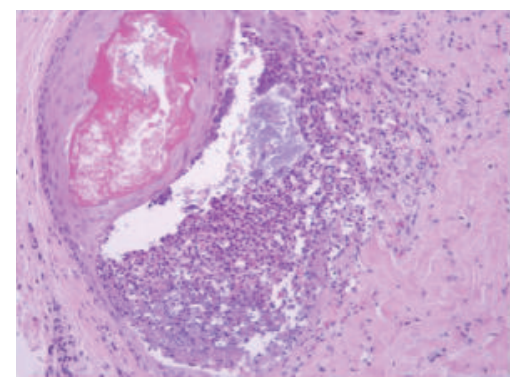

(b)

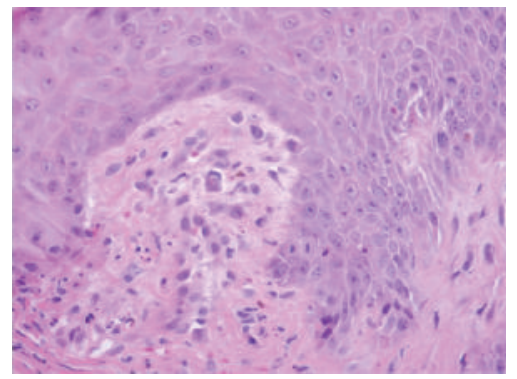

(d)

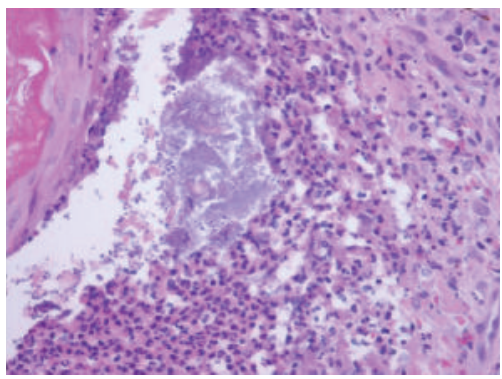

(c)

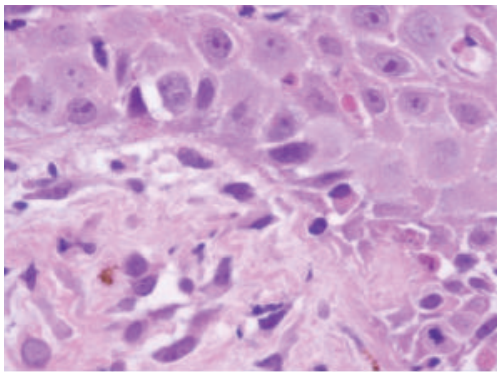

(e)

FIGURE 6: (a) Suppurative folliculitis (black arrow) associated with interface dermatitis (red arrow), the latter ascribed to recently introduced HAART. There is a florid folliculocentric neutrophilic infiltrate (b), with the lumen of the partially disrupted follicle containing both Staphylococcus organisms and Malassezia yeasts (c). Drug-induced pauci-inflammatory interface dermatitis is observed in the neighbouring epidermis (d, e). (By courtesy of Dr. J. Rigby, National Health Laboratory Service and the University of the Witwatersrand, Johannesburg, South Africa.)

Cutaneous infection with Pneumocystis jiroveci (formerly P. carinii) is a rare complication of HIV/AIDS. There have, however, been single case reports of coinfection with other organisms, namely, botryomycosis due to concomitant Staphylococcus aureus infection, and skin lesions harboring both Pneumocystis organisms and Cryptococcus neoformans yeasts $[18,19]$. BA has been reported in association with Mycobacterium avium-intracellulare (MAI) infection [5, 20]. Cases with lesions containing three separate infective organisms are discussed in Section 2.8 . 


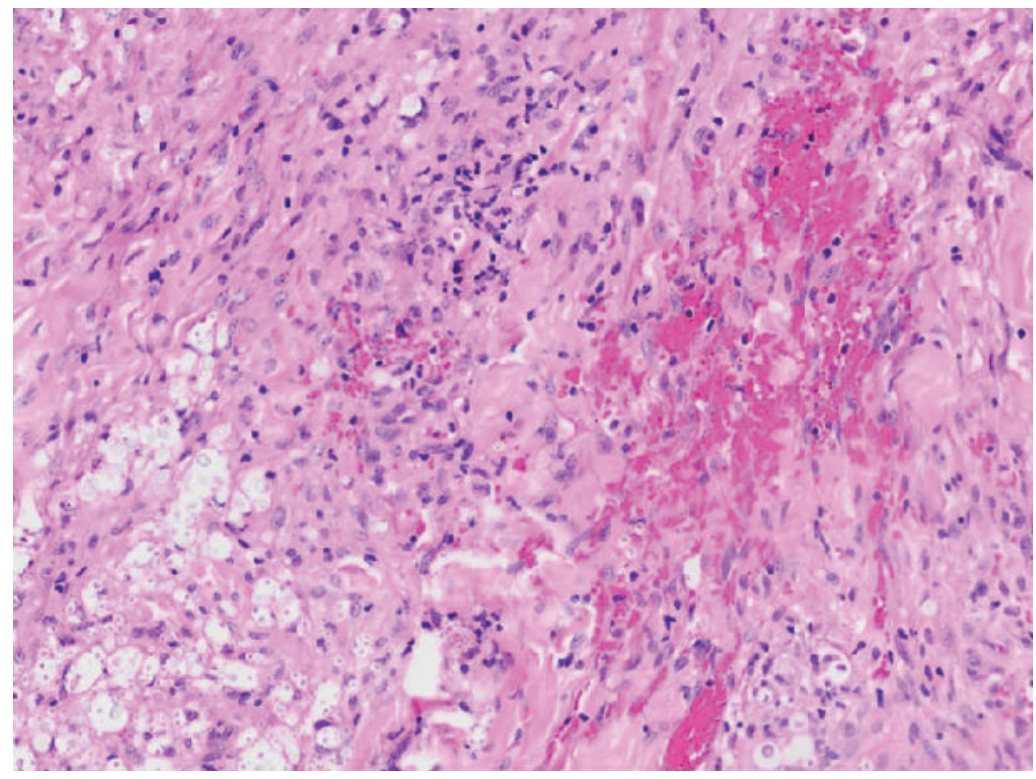

(a)

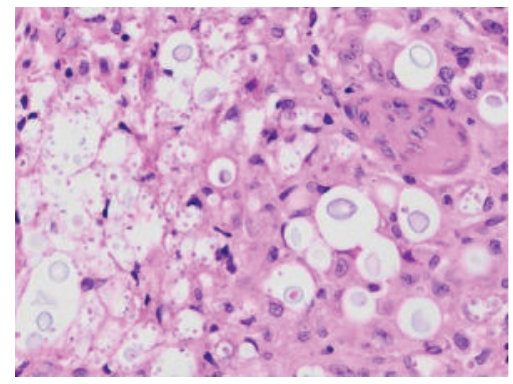

(b)

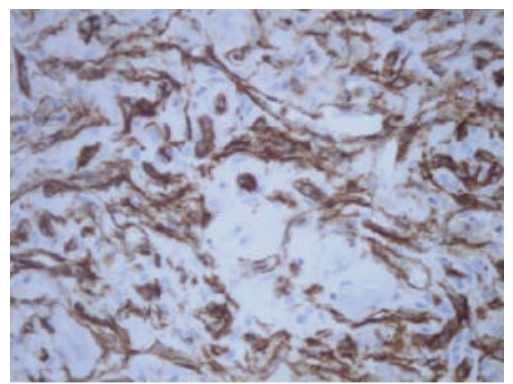

(d)

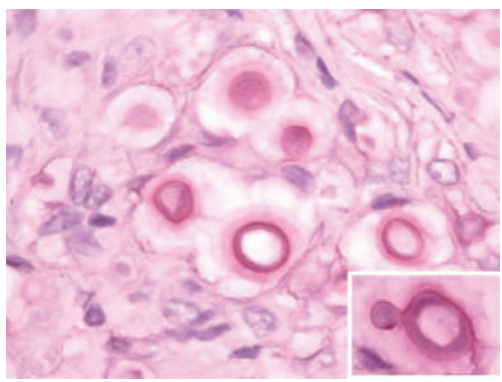

(c)

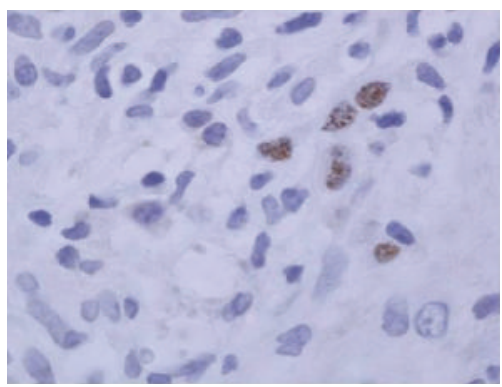

(e)

FIGURE 7: (a) AIDS-associated Kaposi sarcoma with concomitant cutaneous cryptococcosis. Cryptococcus neoformans yeasts (including capsule deficient forms) are present amid the background spindle cell proliferation (b), with the mucicarmine preparation (c) highlighting the mucoid capsule around individual yeasts; narrow-based budding is present (inset). The KS lesional cells demonstrate immunoreactivity for both CD31 (d) and human herpes virus type 8 (HHV-8) (e).

2.4. Dual Infective and Noninfective Dermatoses. This phenomenon has, to the best of one's knowledge, not been addressed in the literature. Vacuolar interface dermatitis is a reaction pattern with a number of potential causes in patients with HIV/AIDS. Causes are diverse, including the acute exanthem of HIV infection, a morbilliform drug rash, erythema multiforme, and so-called AIDS interface dermatitis [1]. Doubt has been expressed regarding the validity of the latter as a distinct clinicopathological entity, as a significant proportion of patients whose biopsies revealed interface dermatitis had one or more opportunistic infections and/or had been receiving one or more drugs at 


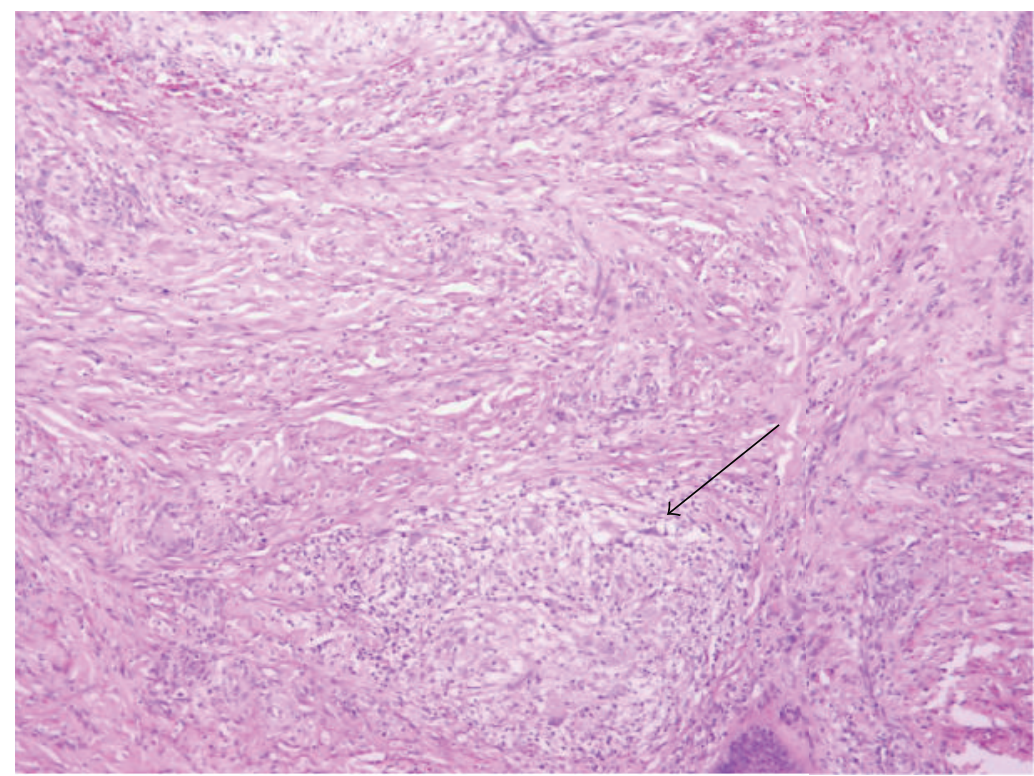

(a)

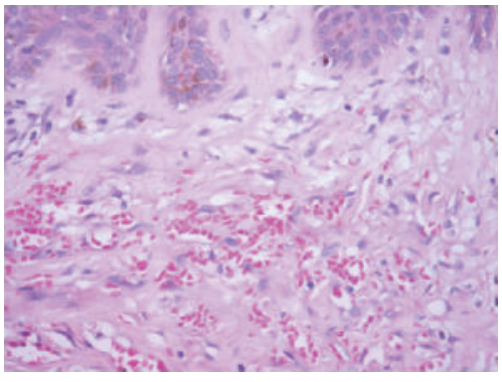

(b)

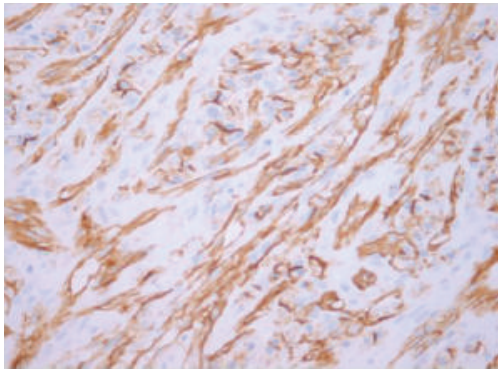

(d)

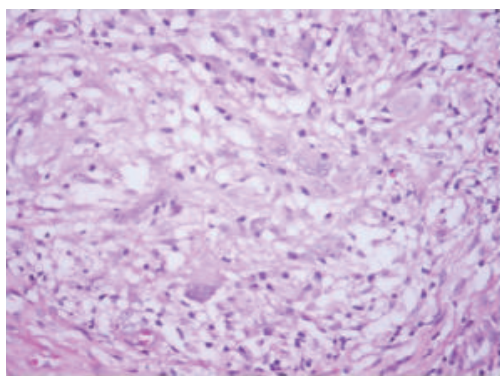

(c)

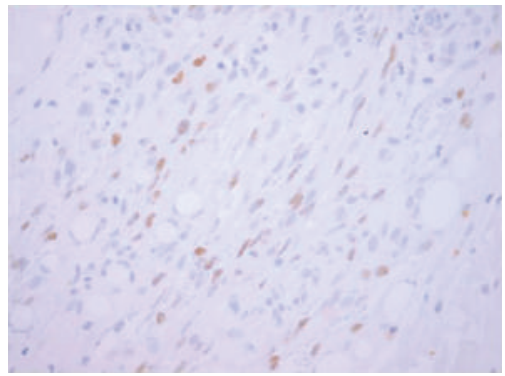

(e)

FIGURE 8: (a) Facial Kaposi sarcoma (KS) in an adult man undergoing treatment for pulmonary tuberculosis. A noncaseating granuloma is present within the KS lesion in the lower half of the field (arrow). (b) Detail of the vasoformative KS proliferation. (c) Higher magnification of the tuberculous granuloma. Although acid-fast bacilli could not be demonstrated on Ziehl-Neelsen staining, mycobacterial DNA was detected by PCR. (d) CD31 immunostain highlighting the background KS. (e) The KS lesional cells were also immunoreactive for HHV-8.

the time of diagnosis $[1,6,21,22]$. There are nevertheless occasions in which interface dermatitis is detected coincidentally in a biopsy performed for another reason (e.g., confirmation of KS) and in which there is no significant drug history (see below) $[1,6]$. The author has encountered cases where careful clinical correlation has elucidated the cause of this reaction pattern when a skin biopsy has been performed for confirmation of another condition. Anecdotal examples include histoplasmosis with erythema multiforme (Figure 5), and folliculitis in association with an adverse drug reaction to HAART (Figure 6).

2.5. Neoplasia in Association with Infection. KS skin lesions may rarely contain coincidental infective organisms. Failure 


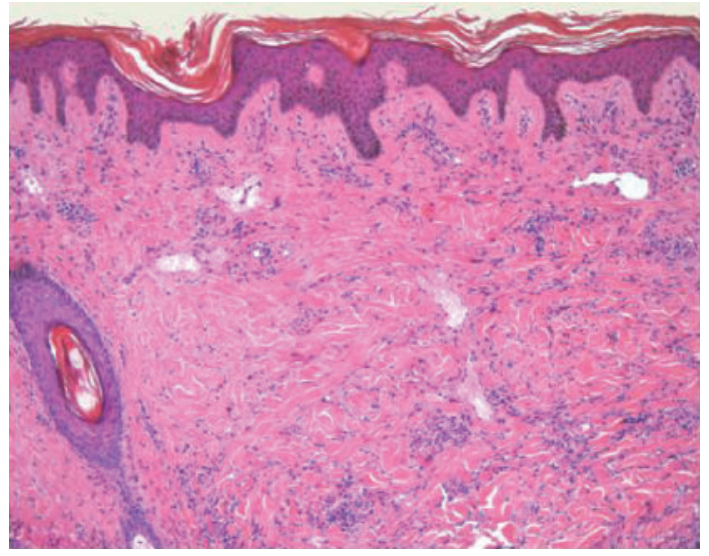

(a)

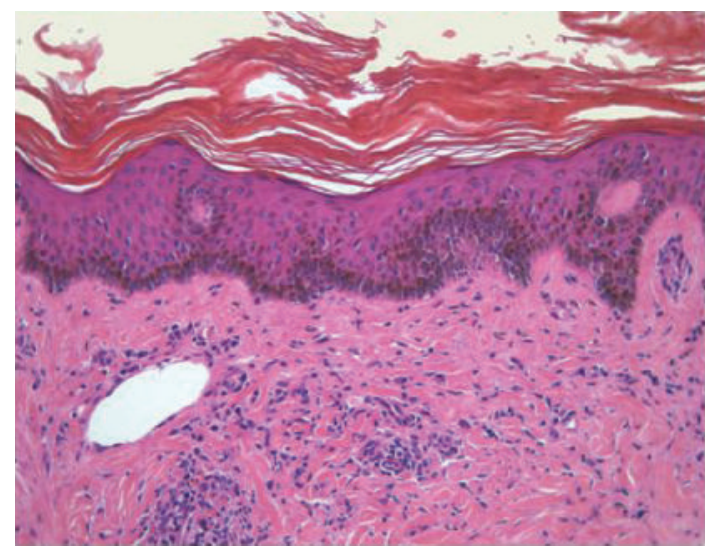

(b)

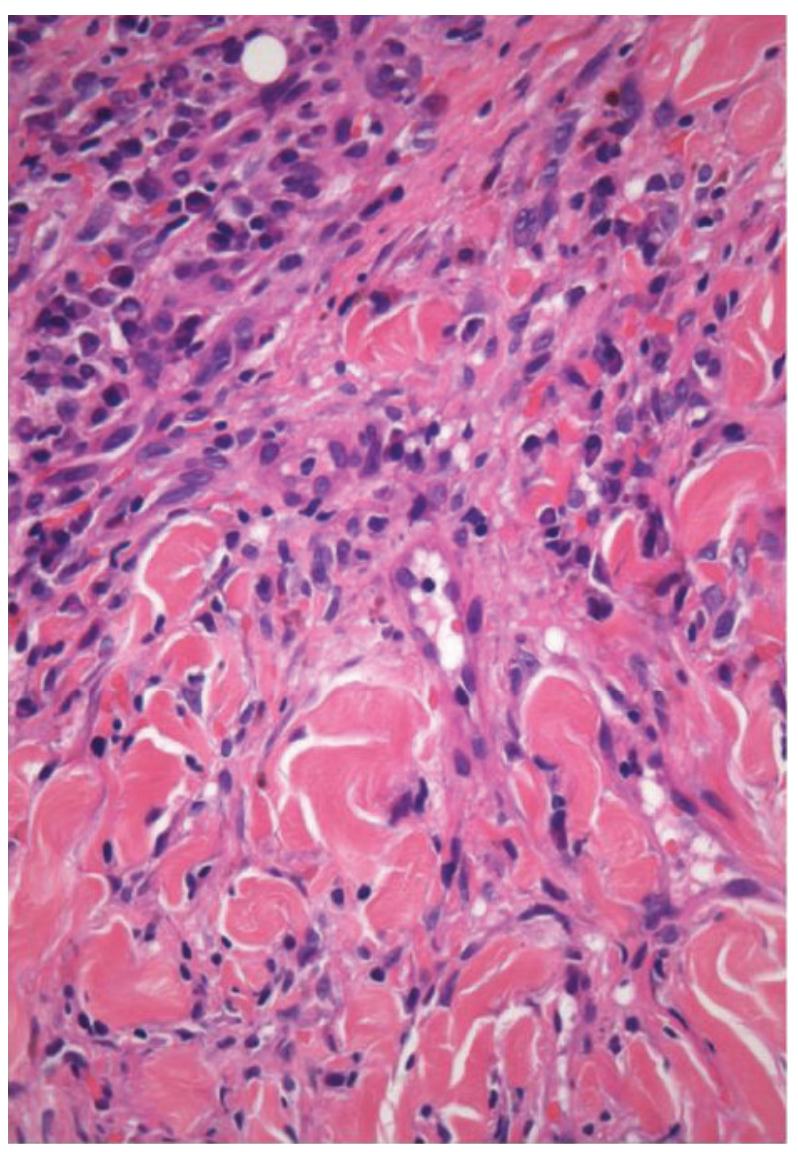

(c)

FIGURE 9: Skin biopsy from a patient with HIV-associated acquired ichthyosis and Kaposi sarcoma. The epidermis displays prominent hyperkeratosis $(\mathrm{a}, \mathrm{b})$, while the underlying dermis is expanded by a typical plaque-stage Kaposi sarcoma proliferation (c).

to recognise the opportunistic pathogen, whose presence is often masked by the more obvious background spindle cell proliferation, could have grave prognostic implications. To date there have been only nine recorded cases of AIDSassociated KS with colesional cryptococcosis, one of whom had oral lesions exclusively [4, 23-27]. The author has encountered three additional examples of KS with incidental Cryptococcus neoformans infection, including the case illustrated in Figure 7.

Histoplasma capsulatum coexistent with $\mathrm{KS}$ in a single lesion has also been reported [28]. In this context, $H$. capsulatum yeasts should be distinguished from infection with capsule deficient forms of $C$. neoformans occurring in association with KS $[3,4]$. There are two documented cases of KS with apparent intralesional Candida organisms. The latter were identified on ultrastructural examination [29]. Although there are rare reports of patients with concurrent $\mathrm{KS}$ and BA, these cases seem to have presented with separate lesions, showing no apparent microscopic evidence of BA in the KS histological specimens and vice versa [30-32].

MAI infection has uncommonly been documented in association with KS, including one patient who had a facial non-Hodgkin lymphoma of immunoblastic type containing acid-fast organisms, and another who had concomitant colesional cryptococcosis [26, 33-35]. More recently, $M$. tuberculosis has also been detected in KS cutaneous lesional tissue (Figure 8), where its presence may serve as a clue to underlying HIV infection, systemic tuberculosis, noncompliance to antituberculous medication, or multidrug resistant tuberculosis [36]. Although these tuberculoid granulomas are recognised with relative ease in involved KS lesions, mycobacterial spindle cell tumours concomitant with KS may pose a particular diagnostic challenge [3]. This latter phenomenon has been described in the lymph nodes of HIV+ patients but has not, to the best of one's knowledge, been documented in the skin [37].

Not unexpectedly, KS may occasionally harbour CMV inclusions, including KS involving the oral cavity [3, 38, 39]. Although the clinical significance thereof is the subject of debate, the identification of CMV inclusions in KS may serve as a sentinel for more serious systemic CMV disease such as retinitis or pneumonitis $[3,38]$. The fortuitous detection of molluscum contagiosum in KS has also been reported; the presence of both lesions in a single histological specimen may be the first clue to underlying HIV infection/AIDS $[3,40]$. 


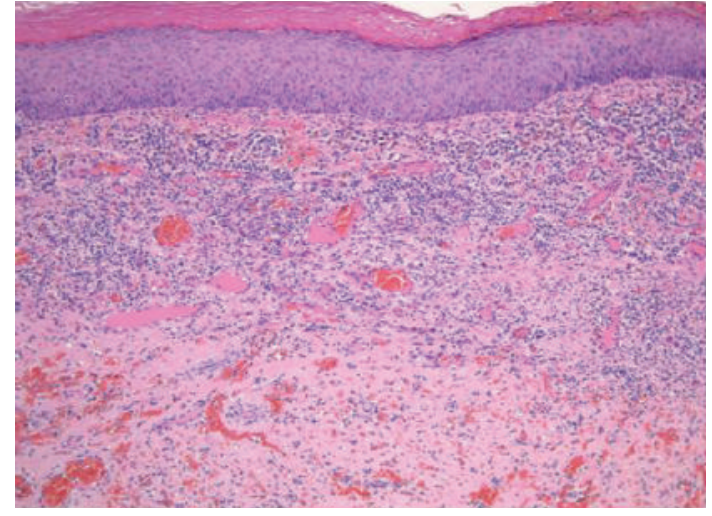

(a)

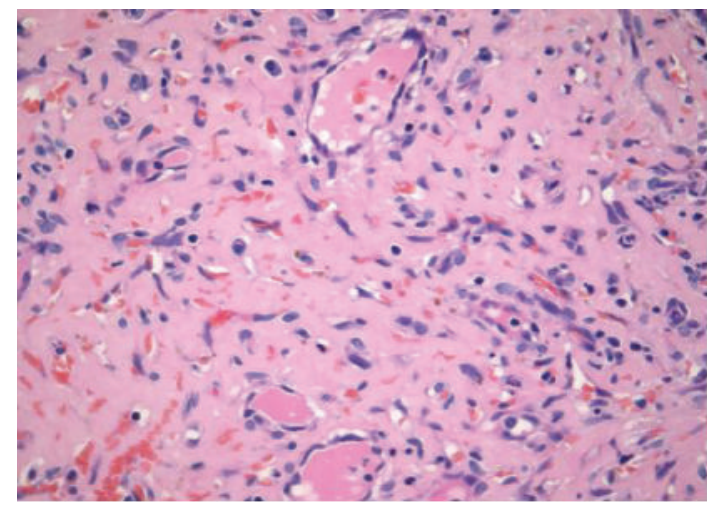

(b)

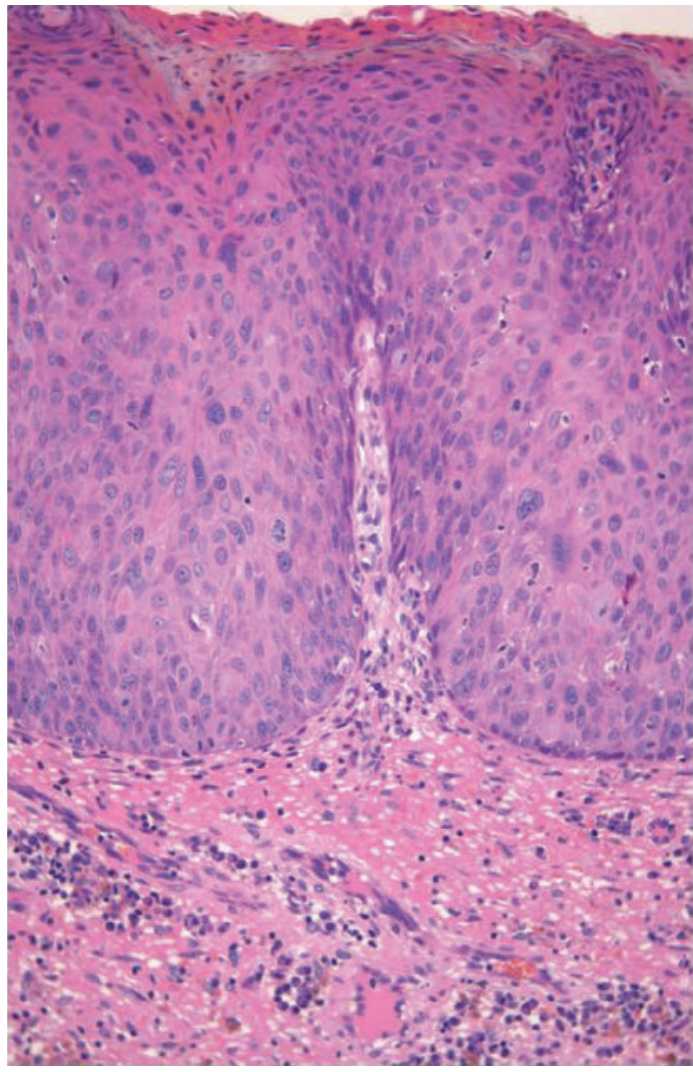

(c)

Figure 10: (a) Penile squamous cell carcinoma in situ in association with genital Kaposi sarcoma. (b) Detail of the Kaposi sarcoma proliferation replacing the subepithelial stroma. (c) Severe dysplasia involving the full thickness of the overlying surface epithelium.

2.6. Neoplasia in Association with Noninfective Dermatoses. Since patients with HIV/AIDS often present with cutaneous lesions caused by more than one disease, it is not entirely unexpected that biopsies performed for histological confirmation of KS may sometimes show evidence of a concomitant noninfective dermatosis. Although uncommon, it has been the author's experience that incidental interface dermatitis is encountered occasionally in the epidermis overlying a KS lesion $[6,41]$. While some examples are almost certainly attributable to a concurrent adverse drug reaction, some cases have no significant pharmacological history and could perhaps represent examples of so-called "AIDS interface dermatitis" [1, 6, 21, 22].

There is a well-documented association between AIDS and acquired ichthyosis, including patients who have presented with concomitant KS [42-44]. Biopsies from such patients may therefore reveal histological features of both conditions, as depicted in Figure 9 [41]. The latter biopsy was intentionally obtained from an area of ichthyosis overlying a suspected dermal KS lesion on the lower extremity.

2.7. Dual Neoplastic Lesions. AIDS carries an increased risk of oral and anogenital neoplasia $[6,45,46]$. Rarely, biopsies of KS genital lesions may reveal coincidental squamous cell carcinoma in situ, as illustrated in Figure 10 [41].
2.8. Multiple Pathology. Although rare, single histological specimens may occasionally reveal more than two pathological lesions. This rare phenomenon has been documented in single case reports. Most comprise either three separate infections, or two infections in association with KS. Recorded examples include the following:

(i) BA, MAI, and CMV coinfection $[47,48]$,

(ii) Concurrent CMV, MAI, and M. tuberculosis infection [49],

(iii) Infection with S. aureus, CMV, and Mycobacterium spp. [50],

(iv) MAI, KS, \& Cryptococcus infection [26], and

(v) varicella-zoster virus (VZV) infection, leucocytoclastic vasculitis, and KS (Figure 11) [1].

The patient whose biopsy is depicted in Figure 11 had purple-red KS lesions and an associated vesicular eruption. The sample was intentionally obtained from a somewhat haemorrhagic lesion on the trunk, where a vesicle was observed on the surface of a clinical KS lesion.

\section{Conclusion}

Colesional pathology may easily be overlooked in skin biopsies from patients with HIV/AIDS, especially when 

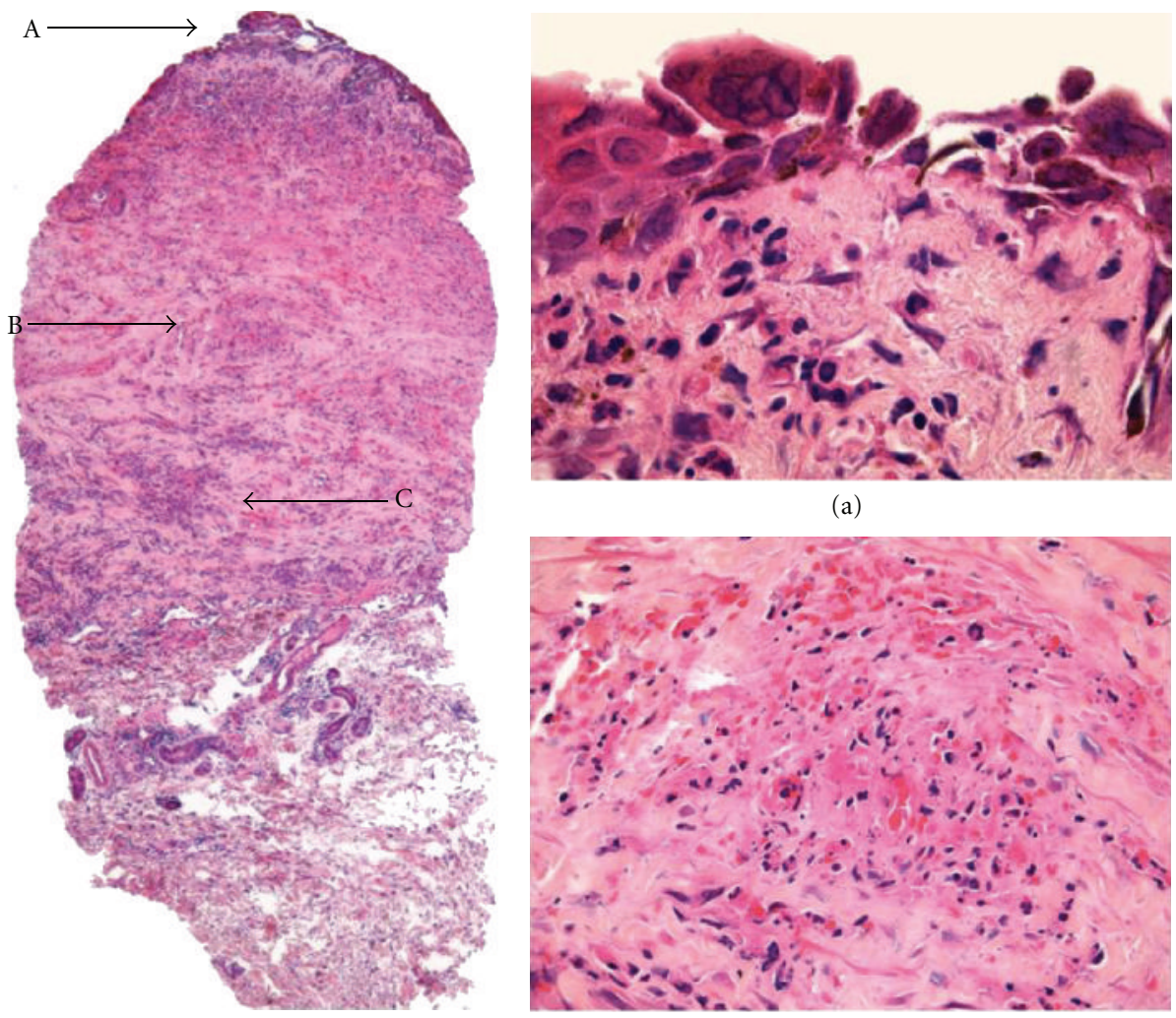

(a)

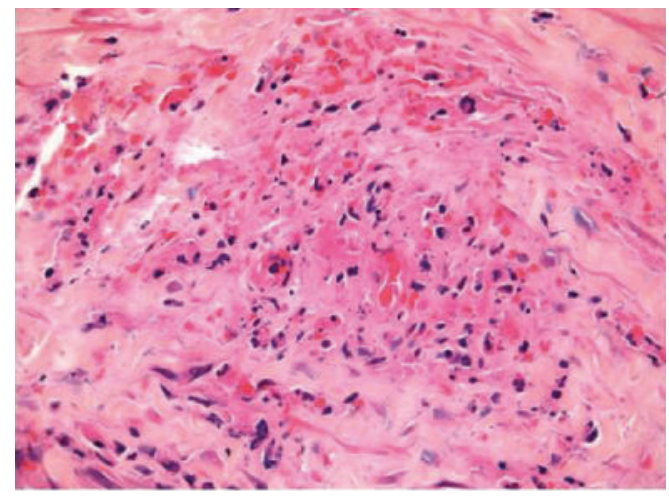

(b)

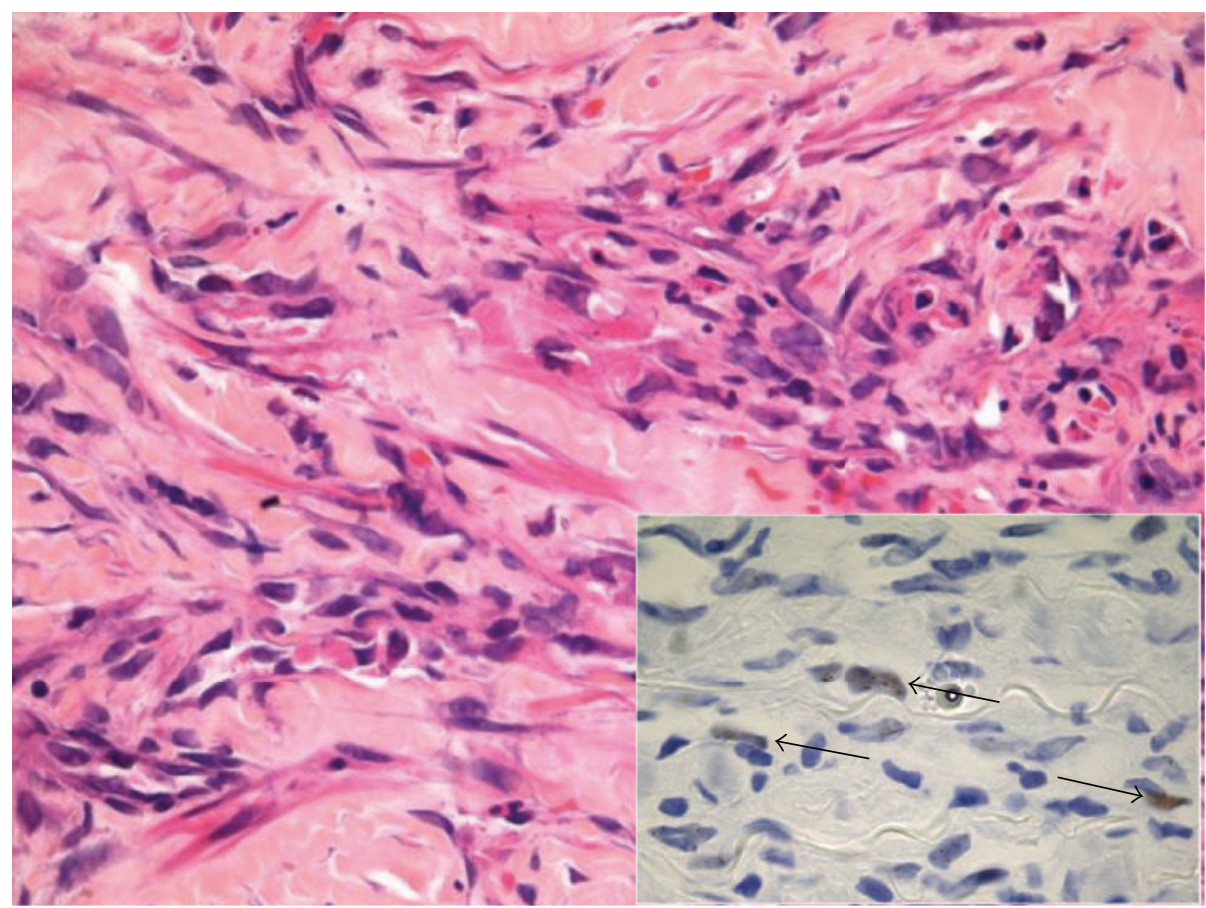

(c)

Figure 11: Skin biopsy demonstrating multiple HIV/AIDS-related pathology, including a superficial vesicle due to varicella-zoster virus infection (a), leucocytoclastic vasculitis in the mid- to upper dermis (b), and incidental Kaposi sarcoma in the deeper dermis (c), the latter confirmed by immunohistochemical staining for HHV-8 (inset). (Reproduced from [1] with permission from BMJ Publishing Group Ltd.). 
the primary pathological lesion dominates the histological picture. It is wise for the surgical pathologist to always consider dual or multiple pathology when examining biopsy material from this group of patients. Rigorous adherence to this principle when studying the routine haematoxylin and eosin (H\&E) stained sections will usually facilitate diagnosis or at least raise suspicion for a second or perhaps even a third pathological process. Since it is neither practical nor cost-effective to perform a panel of histochemical and/or immunohistochemical stains for potential identification of infectious organisms on each and every biopsy, relevant stains should be reserved for confirmation of one's suspicion based on the H\&E findings. If necessary, additional biopsies should be recommended for appropriate microbiological studies, such as fungal culture. A clinical history of polymorphous skin lesions should alert the pathologist to the potential for dual or multiple pathology in a given skin biopsy.

CMV remains the most frequently encountered coincidental pathogen, and whilst its precise pathological significance is often uncertain, one should remain cognisant that the presence of CMV inclusions in a skin biopsy may serve as a sentinel for more serious systemic involvement [3]. The detection of tuberculous granulomas or Cryptococcus organisms in KS has similar implications [3, 4, 36]. Although the patients whose biopsies are illustrated herein were largely HAART-naïve, awareness that colesional pathology may be a rare manifestation of IRIS is appropriate in the era of HAART. A potentially interesting collaborative research opportunity may reside in a detailed clinicopathological analysis of a series of such cases.

\section{Acknowledgment}

Mr. Eric Liebenberg, Division of Anatomical Pathology, University of the Witwatersrand, Johannesburg is thanked for his assistance with the photomicrography.

\section{References}

[1] W. Grayson, "The HIV-positive skin biopsy," Journal of Clinical Pathology, vol. 61, no. 7, pp. 802-817, 2008.

[2] S. T. Hartshorne, "Dermatological disorders in Johannesburg, South African," Clinical and Experimental Dermatology, vol. 28, no. 6, pp. 661-665, 2003.

[3] P. K. Ramdial, "Dermatopathological challenges in the human immunodeficiency virus and acquired immunodeficiency syndrome era," Histopathology, vol. 56, no. 1, pp. 39-56, 2010.

[4] P. K. Ramdial, Y. Sing, S. Subrayan, and E. Calonje, "Cutaneous colesional acquired immunodeficiency syndrome associated Kaposi sarcoma and cryptococcosis," American Journal of Dermatopathology, vol. 32, no. 8, pp. 780-786, 2010.

[5] S. D. Lawn, T. A. Bicanic, and D. C. Macallan, "Pyomyositis and cutaneous abscesses due to mycobacterium avium: an immune reconstitution manifestation in a patient with AIDS," Diagnostic Molecular Pathology, vol. 1, no. 3, pp. 212-216, 1992.

[6] P. K. Ramdial and W. Grayson, "Human immunodeficiency virus (HIV) and acquired immunodeficiency syndrome (AIDS)-associated cutaneous diseases," in McKee's Pathology of the Skin, E. Calonje, T. Brenn, A. Lazar, and P. H. McKee, Eds., Elsevier, Philadelphia, Pa, USA, 4th edition, 2011.
[7] F. Rongioletti, G. Ghigliotti, R. De Marchi, and A. Rebora, "Cutaneous mucinoses and HIV infection," British Journal of Dermatology, vol. 139, no. 6, pp. 1077-1080, 1998.

[8] R. B. Odom, W. D. James, and T. G. Berger, "Papular mucinosis and AIDS," in Andrews' Diseases of the Skin: Clinical Dermatol$o g y$, R. B. Odom, W. D. James, and T. G. Berger, Eds., p. 207, W.B. Saunders, Philadelphia, Pa, USA, 9th edition, 2000.

[9] J. Bhawan, S. Gellis, A. Ucci, and T. W. Chang, "Vesiculobullous lesions caused by cytomegalovirus infection in an immunocompromised adult," Journal of the American Academy of Dermatology, vol. 11, no. 4, part 2, pp. 743-747, 1984.

[10] K. J. Smith, H. G. Skelton III, W. D. James, and P. Angritt, "Concurrent epidermal involvement of cytomegalovirus and herpes simplex virus in two HIV-infected patients," Journal of the American Academy of Dermatology, vol. 25, no. 3, pp. 500-506, 1991.

[11] M. Moodley, R. Chetty, and J. Moodley, "Vulval cytomegalovirus coexisting with herpes simplex virus in a patient with human immunodeficiency virus infection," BJOG, vol. 110, no. 12, pp. 1123-1124, 2003.

[12] P. Hofman, J. P. Lacour, J. F. Michiels, M. C. Saint-Paul, and C. Perrin, "Bacillary angiomatosis and cutaneous cytomegalovirus infections in AIDS: a fortuitous association?Angiomatose bacillaire et infection à cytomégalovirus cutanées au cours du SIDA: une association fortuite?" Annales de Pathologie, vol. 13, no. 3, pp. 194-195, 1993.

[13] J. S. Samant, S. H. Namgoong, T. Parveen, and H. P. Katner, "Cytomegalovirus vasculitis and mucormycosis coinfection in late-stage HIV/AIDS," American Journal of the Medical Sciences, vol. 333, no. 2, pp. 122-124, 2007.

[14] B. Tan, C. M. Weldon-Linne, D. P. Rhone, C. L. Penning, and G. S. Visvesvara, "Acanthamoeba infection presenting as skin lesions in patients with the acquired immunodeficiency syndrome," Archives of Pathology and Laboratory Medicine, vol. 117, no. 10, pp. 1043-1046, 1993.

[15] H. J. Helton, M. Loveless, and C. R. White Jr, "Cutaneous acanthamoeba infection associated with leukocytoclastic vasculitis in an AIDS patient," American Journal of Dermatopathology, vol. 15, no. 2, pp. 146-149, 1993.

[16] G. J. Murakawa, T. McCalmont, J. Altman et al., "Disseminated acanthamebiasis in patients with AIDS: a report of five cases and a review of the literature," Archives of Dermatology, vol. 131, no. 11, pp. 1291-1296, 1995.

[17] M. S. Torno Jr., R. Babapour, A. Gurevitch, and M. D. Witt, "Cutaneous acanthamebiais in AIDS," Journal of the American Academy of Dermatology, vol. 42, no. 2, part 2, pp. 351-354, 2000.

[18] P. Saadat, R. Ram, S. Sohrabian, and M. S. Vadmal, "Botryomycosis caused by Staphylococcus aureus and Pneumocystis carinii in a patient with acquired immunodeficiency disease," Clinical and Experimental Dermatology, vol. 33, no. 3, pp. 266-269, 2008.

[19] B. Sandler, T. S. Potter, and K. Hashimoto, "Cutaneous Pneumocystis carinii and Cryptococcus neoformans in AIDS," British Journal of Dermatology, vol. 134, no. 1, pp. 159-163, 1996.

[20] P. M. Sagerman, D. A. Relman, F. Niroomand, and G. W. Niedt, "Localization of Mycobacterium avium-intracellulare within a skin lesion of bacillary angiomatosis in a patient with AIDS," Diagnostic Molecular Pathology, vol. 1, no. 3, pp. 212-216, 1992.

[21] M. J. Rico, W. P. Lory, E. W. Gould, and N. S. Penneys, "Interface dermatitis in patients with the acquired immunodeficiency syndrome," Journal of the American Academy of Dermatology, vol. 16, no. 6, pp. 1209-1218, 1987. 
[22] W. P. Kory, M. J. Rico, E. Gould, and N. S. Penneys, "Dermatopathologic findings in patients with acquired immunodeficiency syndrome," Southern Medical Journal, vol. 80, no. 12, pp. 1529-1532, 1987.

[23] L. Libow, D. Dobert, and D. Dibulkin, "Co-existent cutaneous cryptococcosis and Kaposi's sarcoma in a patient with the acquired immunodeficiency syndrome," Cutis, vol. 41, no. 2, pp. 159-162, 1988.

[24] M. S. Sofman and E. R. Heilman, "Simultaneous occurrence of Kaposi's sarcoma and Cryptococcus within a cutaneous lesion in a patient with acquired immunodeficiency syndrome," Archives of Dermatology, vol. 126, no. 5, pp. 683-684, 1990.

[25] S. J. Glassman and M. J. Hale, "Cutaneous cryptococcosis and Kaposi's sarcoma occurring in the same lesions in a patient with the acquired immunodeficiency syndrome," Clinical and Experimental Dermatology, vol. 20, no. 6, pp. 480-486, 1995.

[26] T. A. Pietras, C. L. Baum, and B. L. Swick, "Coexistent Kaposi sarcoma, cryptococcosis, and Mycobacterium aviumintracellulare in a solitary cutaneous nodule in a patient with AIDS: report of a case and literature review," Journal of the American Academy of Dermatology, vol. 62, no. 4, pp. 676-680, 2010.

[27] A. Kuruvilla, D. M. Humphrey, and P. Emko, "Coexistent oral cryptococcosis and Kaposi's sarcoma in acquired immunodeficiency syndrome," Cutis, vol. 49, no. 4, pp. 260-264, 1992.

[28] M. C. Cole, P. R. Cohen, K. H. Satra, and M. E. Grossman, "The concurrent presence of systemic disease pathogens and cutaneous Kaposi's sarcoma in the same lesion: Histoplasma capsulatum and Kaposi's sarcoma coexisting in a single skin lesion in a patient with AIDS," Journal of the American Academy of Dermatology, vol. 26, no. 2, part 2, pp. 285-287, 1992.

[29] K. H. Marquart, "Electron microscopy reveals fungal cells within tumor tissue from two African patients with AIDSassociated Kaposi sarcoma," Ultrastructural Pathology, vol. 30, no. 3, pp. 187-192, 2006.

[30] T. G. Berger, J. W. Tappero, A. Kaymen, and P. E. LeBoit, "Bacillary (epithelioid) angiomatosis and concurrent Kaposi's sarcoma in acquired immunodeficiency syndrome," Archives of Dermatology, vol. 125, no. 11, pp. 1543-1547, 1989.

[31] C. M. Rosales, M. D. McLaughlin, T. Sata et al., "AIDS presenting with cutaneous Kaposi's sarcoma and bacillary angiomatosis in the bone marrow mimicking Kaposi's sarcoma," AIDS Patient Care and STDs, vol. 16, no. 12, pp. 573-577, 2002.

[32] E. E. M. Cortes, V. Saraceni, D. Medeiros, and I. Ribeiro, "Bacillary angiomatosis and Kaposi's sarcoma in AIDS," AIDS Patient Care and STDs, vol. 14, no. 4, pp. 179-182, 2000.

[33] A. R. Cantwell Jr., "Kaposi's sarcoma and variably acid-fast bacteria in vivo in two homosexual men," Cutis, vol. 32, no. 1, pp. 58-68, 1983.

[34] S. D. DeCoste and J. S. Dover, "Kaposi's sarcoma and Mycobacterium avium-intracellulare with cellulitis in patients with acquired immunodeficiency syndrome," Journal of the American Academy of Dermatology, vol. 21, no. 3, part 1, pp. 574-576, 1989.

[35] A. R. Cantwell Jr., "Mycobacterium avium-intracellulare infection and immunoblastic sarcoma in a fatal case of AIDS," Growth, vol. 50, no. 1, pp. 32-40, 1986.

[36] P. K. Ramdial, Y. Sing, and S. Subrayan, "Spindle cell tumours associated with mycobacteria in lymph nodes of HIV-positive patients: "Kaposi sarcoma with mycobacteria" and "mycobacterial pseudotumor"', The American Journal of Surgical Pathology, vol. 23, no. 6, pp. 656-661, 1999.
[37] S. Logani, S. Lucas, and J. D. Cheng, "Granulomas in acquired immunodeficiency syndrome-associated Kaposi sarcoma: evidence for a role for mycobacterium tuberculosis," Journal of Cutaneous Pathology, vol. 37, no. 8, pp. 327-334, 2010.

[38] I. Bournérias, S. Boisnic, O. Patey et al., "Unusual cutaneous cytomegalovirus involvement in patients with acquired immunodeficiency syndrome," Archives of Dermatology, vol. 125, no. 4, pp. 1243-1246, 1989.

[39] S. Meer and M. Altini, "Cytomegalovirus co-infection in AIDS-associated oral Kaposi's sarcoma," Advances in Dental Research, vol. 19, no. 1, pp. 96-98, 2006.

[40] B. Cribier, Y. Scrivener, and E. Grosshans, "Molluscum contagiosum: histologic patterns and associated lesions: a study of 578 cases," American Journal of Dermatopathology, vol. 23, no. 2, pp. 99-103, 2001.

[41] W. Grayson and L. Pantanowitz, "Histologic variants of Kaposi sarcoma," in Kaposi Sarcoma: A Model of Oncogenesis, L. Pantanowitz, J. Stebbing, and B. J. Dezube, Eds., pp. 139-159, Research Signpost, Trivandrum, India, 2010.

[42] M. A. Bechtel and J. P. Callen, "Disseminated Kaposi's sarcoma in a patient with acquired ichthyosis," Journal of Surgical Oncology, vol. 26, no. 6, pp. 22-26, 1984.

[43] L. Young and H. K. Steinman, "Acquired ichthyosis in a patient with acquired immunodeficiency syndrome and Kaposi's sarcoma," Journal of the American Academy of Dermatology, vol. 16, no. 2, part 1, pp. 395-396, 1987.

[44] S. Brenner, "Acquired ichthyosis in AIDS," Cutis, vol. 39, no. 5, pp. 421-423, 1987.

[45] K. L. Herman, R. A. Jacoby, and G. Webster, "Pathology of HIV-related skin disease," Clinics in Dermatology, vol. 9, no. 1, pp. 95-110, 1991.

[46] S. Lucas, "The changing global clinical pathology of HIV/ AIDS," Histopathology, vol. 41, no. 10, supplement 2, pp. 61-68, 2002.

[47] C. Rovery, J. M. Rolain, and H. Lepidi, "Bacillary angiomatosis with cytomegaloviral and mycobacterial infections of the palpebral conjunctiva in a patient with AIDS," Ophthalmic Plastic and Reconstructive Surgery, vol. 20, no. 2, pp. 168-170, 2004.

[48] B. C. Edmonson, W. R. Morris, and F. D. Osborn, "Bartonella quintana coinfection with Mycobacterium avium complex and CMV in an AIDS patient: case presentation," Clinical Infectious Diseases, vol. 38, no. 3, pp. 461-463, 2004.

[49] M. Núñez, E. S. Miralles, and Y. Hilara, "Concurrent cytomegalovirus, M. tuberculosis and M. avium-intracellulare cutaneous infection in an HIV patient," The Journal of Dermatology, vol. 24, no. 6, pp. 401-404, 1997.

[50] S. Boudreau, H. C. Hines, and A. F. Hood, "Dermal abscesses with Staphylococcus aureus, cytomegalovirus and acid-fast bacilli in a patient with acquired immunodeficiency syndrome (AIDS)," Journal of Cutaneous Pathology, vol. 15, no. 1, pp. 53-57, 1988. 


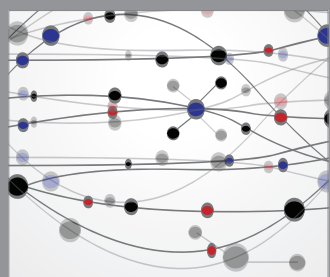

The Scientific World Journal
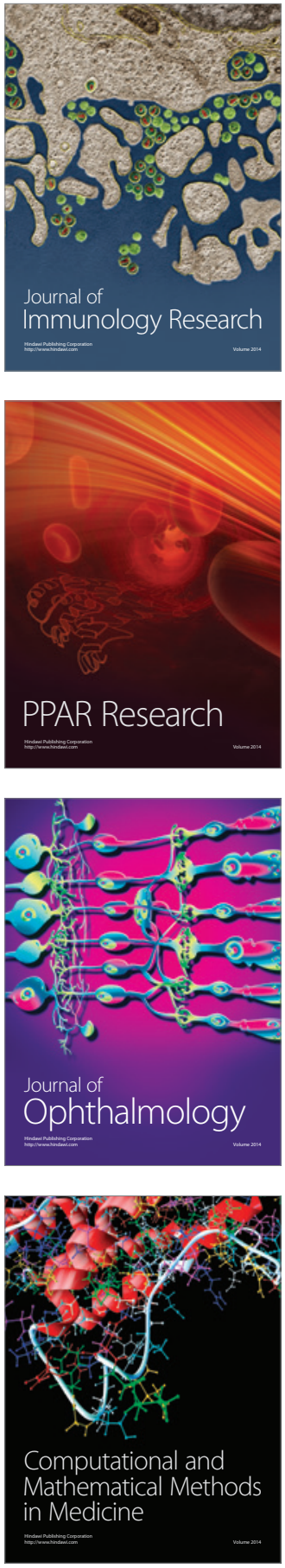

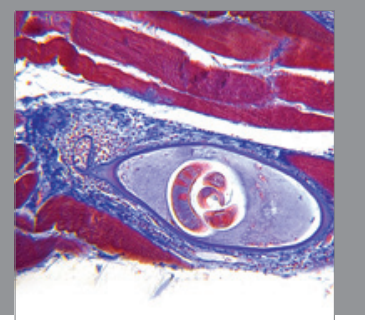

Gastroenterology

Research and Practice
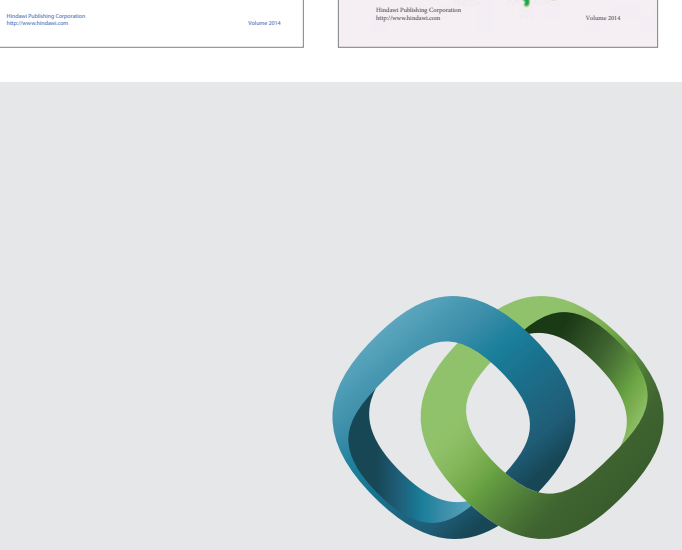

\section{Hindawi}

Submit your manuscripts at

http://www.hindawi.com
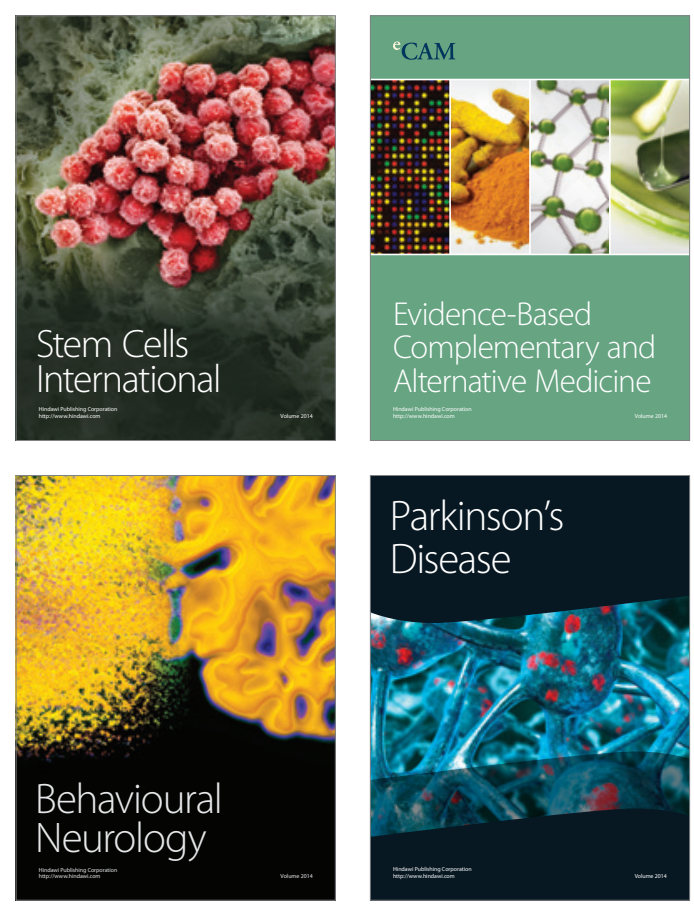

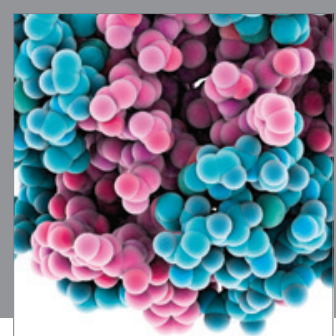

Journal of
Diabetes Research

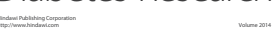

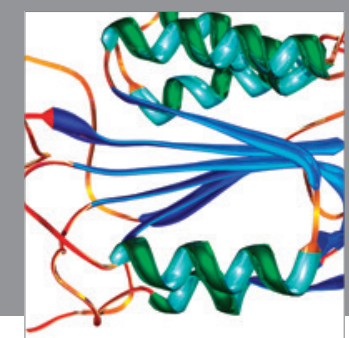

Disease Markers
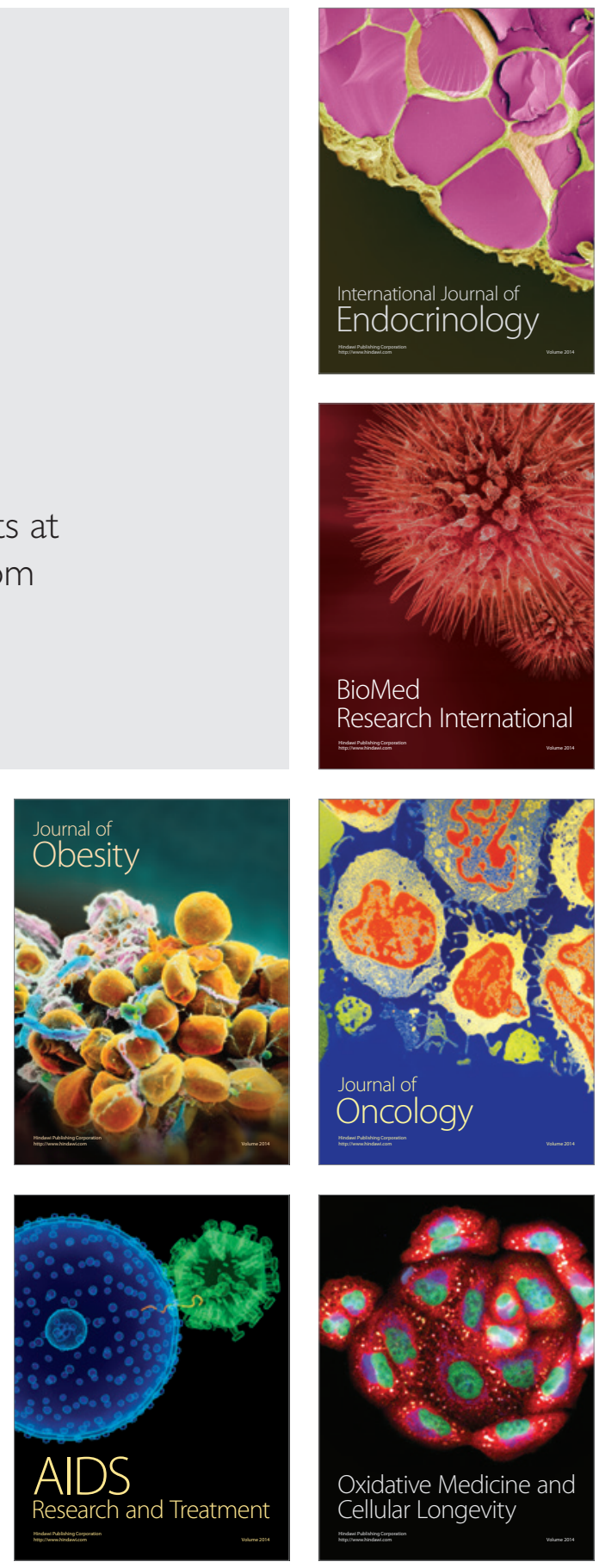